\title{
Diagnostic values of clinical diagnostic tests in subacromial impingement syndrome
}

\author{
Mustafa Çalış, Kenan Akgün, Murat Birtane, Ilhan Karacan, Havva Çalış, Fikret Tüzün
}

\begin{abstract}
Objective-Subacromial impingement syndrome (SIS) is a frequent cause of shoulder pain. The aim of this study was to investigate the diagnostic values of clinical diagnostic tests, in patients with SIS.

Methods-72 female, 48 male patients with shoulder pain were included in the study. Five had bilateral shoulder pain, so 125 painful shoulders were evaluated. Details were recorded about the patients' ages and sexes, as well as characteristics of pain and related problems. Detailed physical examination and routine laboratory tests were performed. Conventional radiography and subsequent magnetic resonance imaging of the shoulder region of all patients were performed. Patients were divided into two groups according to the results of subacromial injection test, a reference standard test for SIS. Test positive patients constituted SIS group and test negative patients the non-SIS group. Sensitivity, specificity, accuracy, positive and negative predictive values of some clinical diagnostic tests such as Neer, Hawkins, horizontal adduction, painful arc, drop arm, Yergason and Speed tests for SIS were determined by using $2 \times 2$ table.
\end{abstract}

Results-The most sensitive diagnostic tests were found to be Hawkins test $(92.1 \%)$, Neer test $(88.7 \%)$ and horizontal adduction test $(82.0 \%)$. Tests with highest specificity were drop arm test $(97.2 \%)$, Yergason test $(86.1 \%)$ and painful arc test $(80.5 \%)$ consecutively.

Conclusion-The highly sensitive tests seem to have low specificity values and the highly specific ones to have low sensitivity values. Although this finding suggests that these diagnostic tests are insufficient for certain diagnosis, it is suggested they play an important part in clinical evaluation.

(Ann Rheum Dis 2000;59:44-47)

Shoulder pain is a common complaint with many diverse aetiologies. ${ }^{1}$ Subacromial impingement syndrome (SIS) is a frequent cause of shoulder pain. ${ }^{23}$ Disorders of rotator cuff tendons have usually been grouped under the diagnostic phrase SIS. ${ }^{4}$

SIS is the compression of the suprahumeral structures against the anteroinferior aspect of the acromion and coracoacromial ligament. The structures most often irritated and inflamed with SIS are the rotator cuff muscles, the long head of the biceps and the subacromial bursa. ${ }^{4-6}$

The main features of SIS were first described by Neer in $1972 .{ }^{5}$ He has classified three stages of SIS. In stage 1: oedema and haemorrhage; in stage 2: cuff fibrosis, thickening and partial cuff tearing; in stage 3: full thickness tendon tears, bony changes and tendon rupture are specific findings. ${ }^{5-7}$ Neer has proposed that $95 \%$ of rotator cuff tears occur as a consequence of SIS. ${ }^{5-8}$

Many clinical diagnostic tests have been developed for physical examination of shoulder some of which are Hawkins, Neer, horizontal adduction, painful arc, drop arm, Yergason and Speed tests. ${ }^{910}$ These tests may be positive in SIS and shoulder disorders other than SIS. For differential diagnosis, subacromial injection test (SIT), a reference standard test for the diagnosis of this syndrome, should be performed. $^{681112}$ Marked relief of pain and almost total improvement in passive and/or active shoulder range of motion (ROM) after SIT suggest the test is positive and that discriminates SIS from other shoulder pathologies. SIT positive cases are considered to have SIS, unless they have calcific lesions in conventional radiography.

Although the clinical diagnostic tests are used frequently for clinical evaluation, not much data on their diagnostic value are available. Our aim was to investigate the diagnostic value of these tests in SIS diagnosis. We evaluated sensitivity, specificity, accuracy, positive and negative predictive values of the clinical diagnostic tests for SIS.

\section{Methods}

This study was performed on 120 patients with shoulder pain either referred from rheumatology and orthopaedic surgery units or directly applied to the Department of Physical Medicine and Rehabilitation in Cerrahpasa Faculty of Medicine. Five of them had bilateral shoulder pain. In total 125 painful shoulders were examined. Of the patients, $72(60 \%)$ were female and $48(40 \%)$ were male. Patients between the ages 18 and 70 were included in the study. Patients, having any of the following disorders were excluded: (1) inflammatory or systemic diseases, (2) acute traumatic conditions, (3) postoperative conditions and (4) neck and elbow disorders.

Details were recorded about the patients' ages, sexes, occupations, characteristics of pain and additional problems. Detailed physical examination and routine laboratory tests were performed. Conventional radiography and magnetic resonance imaging (MRI) of shoulder 
region of all patients were performed and evaluated by a radiologist who had experience on skeletal system, especially on shoulder imaging.

After clinical diagnostic tests were applied on all patients by two physicians who had four and eight years of experience in shoulder management. The interobserver reliability values for these tests were above $98 \%$.

NEER TEST

While scapular rotation is prevented with one hand, the arm of the patient is forced to elevation at an angle between flexion and abduction, by the other hand. Test is positive if pain occurs. ${ }^{568}$

HAWKINS TEST

The arm of the patient is flexed up to 90 degrees and then forced to internal rotation. If pain occurs, the test is then positive. ${ }^{3}$

HORIZONTAL ADDUCTION TEST

The arm is forced to adduction towards the other shoulder while the elbow is flexed. If pain occurs, this suggests the test is positive. ${ }^{1013}$

PAINFUL ARC TEST

Pain occurs between the angle of 60 and 120 degrees of shoulder abduction. ${ }^{13}$

DROP ARM TEST

The patient is asked to abduct his shoulder to 90 degrees and then to let the arm down slowly. If the patient cannot do this and the arm drops immediately with pain, the test is then positive. ${ }^{9}{ }^{13}$

YERGASON TEST

The elbow is flexed to 90 degrees and the forearm is pronated. With the examining physician holding the patient's wrist, the patient is directed to actively supinate against resistance. If pain is localised to the bicipital groove area, this suggests disorder in the long head of the biceps tendon in its sheath. ${ }^{14}$

\section{SPEED TEST}

With the elbow extended and the forearm supinated, forward elevation of the humerus to approximately 60 degrees is resisted. A positive result of this test elicits pain localised to the bicipital groove area. ${ }^{913}$

We performed SIT, a reference standard test for SIS. SIT was used to classify patients in two groups but without implying any knowledge about the underlying disorder. One per cent, $10 \mathrm{cc}$ lignocaine (lidocaine) was injected into subacromial space just under acromion using anterior approach by experienced hands. Having identified the acromioclavicular joint and

Table 1 Age and sex distribution of patients

\begin{tabular}{lllllll}
\hline & \multicolumn{2}{l}{ Women } & & & \multicolumn{2}{c}{ Men } \\
\cline { 2 - 3 } & Number & $\%$ & & Number & $\%$ & Age mean (SD) \\
\hline SIS patients & 51 & 42.5 & & 35 & 29.2 & $52.5(14.8)$ \\
Non-SIS patients & 21 & 17.5 & & 13 & 10.8 & $48.9(11.2)$ \\
Total & 72 & 60.0 & & 48 & 40.0 & $51.6(13.9)$ \\
\hline
\end{tabular}

the anterior edge of the acromion, the aim of the injection is to place the point of the needle immediately below the anterior edge of the acromion. Introduction of the needle was assisted by gentle longitudinal traction on the arm to increase the gap between the acromion and humeral head. No injection was made directly into tendon or the glenohumeral joint. Patients with marked relief of pain and almost total improvement in passive and/or active ROM values, 30 minutes after injection and these patients with no calcific lesions on radiographs were identified as having SIS. Test positive patients constituted SIS group and test negative patients the non-SIS group.

Sensitivity, specificity, accuracy, positive (PPV) and negative predictive values (NPV) of the clinical diagnostic tests for SIS were determined by using $2 \times 2$ table. Also these values were determined one by one for Zlatkin SIS stages based on MRI findings. ${ }^{15}$ Zlatkin stages: Stage 0: tendon morphology and signal intensity normal.

Stage 1: increased signal intensity in the tendon without without any thinning irregularity or discontinuity.

Stage 2: increased signal intensity with irregularity and thinning in the tendon.

Stage 3: complete disruption of the supraspinatus tendon.

Statistical analysis was made in SPSS for Windows program. Average age and disease duration of the groups were compared by unpaired $t$ test. Sensitivity, specificity, accuracy, PPV and NPV were determined by using $2 \times 2$ tables.

\section{Results}

After SIT, 86 of the patients had positive results thus constituted SIS group. One of these patients had bilateral impingement. Nineteen shoulders had stage 1 impingement, 50 shoulders stage 2 and 18 stage 3 . The remaining 34 patients formed the non-SIS group, four of whom had bilateral shoulder pain. Although two patients reacted positively to SIT, they were not accepted to SIS group as calcifications were observed in their radiographs. Of the SIT test negative patients, 19 had the diagnosis of adhesive capsulitis, seven had calcific tendinitis, six had myofascial pain syndrome, three had glenohumeral arthrosis, two had thoracic outlet syndrome and one had primer bicipital tendinitis.

Average of age and sex distributions were not significantly different between two groups $(p>0.05)$ (table 1$)$. Disease duration in two groups were also not different $(p<0.05)$.

The sensitivity, specificity and confidence interval values of Neer, Hawkins, horizontal adduction, painful arc, drop arm, Yergason and Speed tests are shown in table 2 .

The clinical tests that best determined the presence of SIS (the most sensitive ones) were the Hawkins test $(92.1 \%)$, Neer test $(88.7 \%)$ and horizontal adduction test $(82.0 \%)$. Tests that best discriminated non-SIS patients (tests with the highest specificity) were drop arm test $(97.2 \%)$, Yergason test $(86.1 \%)$ and painful arc test $(80.5 \%)$ consecutively. Tests with the 
Table 2 Sensitivity, specificity values and confidence intervals in clinical diagnostic tests

\begin{tabular}{llllll}
\hline & $\begin{array}{l}\text { Sensitivity } \\
(\%)\end{array}$ & $\begin{array}{l}\text { Specificity } \\
(\%)\end{array}$ & $\begin{array}{l}\text { Accuracy } \\
(\%)\end{array}$ & $\begin{array}{l}\text { PPV } \\
(\%)\end{array}$ & $\begin{array}{l}\text { NPV } \\
(\%)\end{array}$ \\
\hline Hawkins & 92.1 & 25.0 & 72.8 & 75.2 & 56.2 \\
Neer & 88.7 & 30.5 & 72.0 & 75.9 & 52.3 \\
Horizontal adduction & 82.0 & 27.7 & 66.4 & 73.7 & 38.4 \\
Speed & 68.5 & 55.5 & 64.8 & 79.2 & 41.6 \\
Yergason & 37.0 & 86.1 & 51.2 & 86.8 & 35.6 \\
Painful arc & 32.5 & 80.5 & 46.4 & 80.5 & 32.5 \\
Drop arm & 7.8 & 97.2 & 33.6 & 87.5 & 29.9 \\
\hline
\end{tabular}

Table 3 Sensitivity, specificity and confidence interval values in test combinations

\begin{tabular}{lllllll}
\hline Positive tests & $\begin{array}{l}\text { Case } \\
\text { number }\end{array}$ & $\begin{array}{l}\text { Sensitivity } \\
(\%)\end{array}$ & $\begin{array}{l}\text { Specificity } \\
(\%)\end{array}$ & $\begin{array}{l}\text { Accuracy } \\
(\%)\end{array}$ & $\begin{array}{l}\text { PPV } \\
(\%)\end{array}$ & $\begin{array}{l}\text { NPV } \\
(\%)\end{array}$ \\
\hline All positive & 5 & 4.4 & 97.2 & 31.2 & 80.0 & 29.1 \\
At least 6 positive & 31 & 30.3 & 88.8 & 47.2 & 87.0 & 34.0 \\
At least 5 positive & 39 & 38.2 & 86.1 & 52.0 & 87.1 & 36.0 \\
At least 4 positive & 74 & 69.6 & 66.6 & 68.8 & 83.7 & 47.0 \\
At least 3 positive & 95 & 84.2 & 44.4 & 72.8 & 78.9 & 44.4 \\
\hline
\end{tabular}

highest positive predictive values were found to be drop arm test $(87.5 \%)$, Yergason test $(86.8 \%)$ and painful arc test $(80.5 \%)$. Highest NPV were $56.2 \%, 52.3 \%$ and $41.6 \%$ for Hawkins, Neer and Speed tests respectively. Accuracy ratio values were the highest for Hawkins test $(72.8 \%)$, Neer test $(72.0 \%)$ and horizontal adduction test $(66.4 \%)$.

The sensitivity and specificity of combinations with three, four, five, six and seven clinic diagnostic tests are shown in table 3. According to the results, the more clinical tests existed in the combination, the more the sensitivity but the less the specificity were observed.

Sensitivity, specificity and confidence interval values of clinical diagnostic tests in Zlatkin stage 1, 2 or 3 patients according to MRI are shown in table 4 . Sensitivity, specificity and confidence interval values of diagnostic tests increased as the Zlatkin stages advanced. Especially in Zlatkin stage 3 patients, sensitivity of Hawkins test and the specificity of drop arm test were found out to be $100 \%$.

\section{Discussion}

Disorders that cause painful shoulder exhibit similar clinical symptoms, thus confuse the differential diagnoses. Adhesive capsulitis, calcific tendinitis, myofascial pain syndrome and glenohumeral joint osteoarthritis may be confused in some patients with SIS. Physical examination, although having a great importance, may not be sufficient for appropriate diagnosis. The sensitivity of diagnosis of SIS by physical examination was $73 \%$ in 45 patients with shoulder pain who had the certain diagnosis by arthroscopy. ${ }^{16}$ More than 20 clinical diagnostic tests exist for SIS diagnosis in clinical practice. ${ }^{9}{ }^{16}$ However, we found only a few studies investigating diagnostic values of these tests in literature. ${ }^{913}$

A clinical test should discriminate sick and healthy people to be called a diagnostic test. ${ }^{17}$ Various diagnostic methods have been used for discrimination of SIS from other disorders. Neer used shoulder arthrography in rotator cuff tears and he found sensitivity and specificity of this method to be high only for stage 3 SIS patients with total rotator cuff tears, not for the ones with partial tears. ${ }^{8}$ The overall accuracy of ultrasound, a non-invasive imaging method was 95\%, when compared with surgical findings. ${ }^{18}$ However other authors have not reported the same degree of reliability; therefore ultrasound is recommended only if an experienced technician is available. ${ }^{19}{ }^{20} \mathrm{MRI}$ is a valuable method capable of demonstrating partial tears and tendinitis in stage 1 and 2 SIS. But despite its high sensitivity, its specificity was not determined to be so. ${ }^{21}$ We preferred SIT as a reference standard for classifying patients into two groups of either SIS or not. However, calcific tendinitis and calcific subacromial bursitis may cause the same symptoms as SIS and it should not be forgotten that SIT may alleviate pain in those disorders. ${ }^{6}{ }^{12} 22$

Patients with SIS usually perceive pain when a compressing force is applied on tuberculum majus and rotator cuff region. Also pain may be aggravated with shoulder abduction in internal or external rotation. These manoeuvres constitute the basis of Hawkins and Neer tests. ${ }^{23}$ Pink and Jobe found that rotator cuff tendons were impinged under acromion with Hawkins test and lower surface of the same tendons were impinged in anterosuperior part of glenoid margin with Neer test. ${ }^{24}$ Ure et al, found that the sensitivity of Hawkins test was $62 \%$ and the sensitivity of Neer test was $46 \%$ in 45 patients with stage 2 SIS, by using arthroscopy. ${ }^{16}$ Bak et al suggest that Hawkins test has a higher sensitivity than Neer test for SIS. ${ }^{25}$ Our study confirms these findings. Ure et al found these specificity values as $69 \%$ and $66 \%$ for the same tests, consecutively. These values were not in concordance with ours, perhaps because of different study designs. We included stage 1,2 and 3 patients in this study and used a different method as reference standard. It is clear that Hawkins and Neer tests are quite efficient in diagnosis of SIS as they had high sensitivities. Moreover accuracy ratio of these two tests were found to be higher than the other tests. However, their specificity values were lower than expected. So this lessens their discrimination ability.

Table 4 Sensitivity, specificity and confidence interval values of clinical diagnostic tests in Zlatkin stages

\begin{tabular}{|c|c|c|c|c|c|c|c|c|c|c|c|c|c|c|c|}
\hline & \multicolumn{3}{|c|}{ Sensitivitiy (\%) Zlatkin } & \multicolumn{3}{|c|}{ Specificity (\%) Zlatkin } & \multicolumn{3}{|c|}{ Accuracy (\%) Zlatkin } & \multicolumn{3}{|c|}{ PPV (\%) Zlatkin } & \multicolumn{3}{|c|}{ NPV (\%) Zlatkin } \\
\hline & 1 & 2 & 3 & 1 & 2 & 3 & 1 & 2 & 3 & 1 & 2 & 3 & 1 & 2 & 3 \\
\hline Hawkins & 95.2 & 87.5 & 100 & 30.7 & 23.0 & 35.7 & 59.5 & 64.8 & 73.5 & 52.6 & 67.7 & 68.9 & 88.8 & 50.0 & 100 \\
\hline Neer & 71.4 & 91.6 & 90.0 & 30.7 & 26.9 & 28.5 & 48.9 & 68.9 & 64.7 & 45.4 & 69.8 & 64.2 & 57.1 & 63.6 & 66.6 \\
\hline Horizontal adduction & 61.9 & 83.3 & 90.0 & 30.7 & 23.0 & 28.5 & 44.6 & 54.0 & 64.7 & 50.0 & 66.6 & 64.2 & 41.9 & 42.8 & 66.6 \\
\hline Speed & 52.3 & 64.5 & 85.0 & 57.6 & 50.0 & 57.1 & 55.3 & 59.4 & 73.5 & 50.0 & 70.4 & 73.9 & 60.0 & 43.3 & 72.7 \\
\hline Yergason & 9.5 & 43.7 & 50.0 & 88.4 & 84.6 & 85.7 & 53.1 & 58.1 & 64.7 & 40.0 & 84.0 & 83.3 & 54.7 & 44.8 & 54.5 \\
\hline Painful arc & 9.5 & 37.5 & 45.0 & 88.4 & 73.0 & 78.5 & 53.1 & 50.0 & 58.8 & 40.0 & 72.0 & 75.0 & 54.7 & 38.7 & 50.0 \\
\hline Drop arm & 4.4 & 6.2 & 15.0 & 100 & 96.1 & 100 & 57.4 & 37.8 & 50.0 & 100 & 75.0 & 100 & 56.5 & 35.7 & 45.1 \\
\hline
\end{tabular}


Horizontal adduction test provokes compressing forces on rotator cuff tendons that are localised under acromioclavicular joint. It is a test more likely to be used to investigate acromioclavicular joint osteoarthritis. ${ }^{10}{ }^{13} \mathrm{As}$ the average age of our patients was high, we observed more degenerative lesions of this area in radiographs than expected. So we determined high sensitivity for this test. The low specificity of this test supports this claim.

Speed and Yergason tests more probably discriminate bicipital tendon disorders. However irritation and oedema may occur in the long head of biceps, in any stage of SIS. Biceps tendons may be thickened by fibrinoid degeneration in stage 2 SIS patients. ${ }^{11}$ This may lead to inappropriate diagnosis as primer bicipital tendinitis and subsequent inconvenient tenodesis. In a study, sensitivity of Speed test in biceps tendon disorders was found to be higher than Yergason test. The higher tendon mobilisation capability of this test out of the bicipital groove was suggested as a possible reason for this. ${ }^{95}$ In agreement, we found a higher sensitivity value in Speed test than Yergason test. Despite their lower sensitivity values, Speed test and Yergason test had higher specificity values in our study. This suggests that bicipital tendon is more effected in SIS than the other causes of shoulder pain except for isolated bicipital tendon disorders. Also the addition of bicipital lesions to the clinical picture in the late stages that our patients cumulated, had an impact on the results.

Hermann et al, found that the painful arc test was positive in $48.9 \%$ of 50 patients with degenerative impingement. ${ }^{13}$ Akgün et al observed $57.5 \%$ positive results with the test in stage 2 SIS patients. ${ }^{11}$ For our patients whose average age was high, we observed more acromioclavicular joint degeneration and related pain reaction over 120 degrees of shoulder abduction. As we accepted the test to be negative in those angles, sensitivity of the test was determined to be low. Painful arc test was rarely positive in other disorders of shoulder. Drop arm is a test that is used to clarify whether a rupture is present in rotator cuff or not. Especially it is found positive in stage 3 SIS patients with total rotator cuff rupture. ${ }^{11}$ The most marked result found for this test in our study was its very high specificity and low sensitivity. It is highly possible to claim the diagnosis to be stage 3 SIS, if the test is positive. As we studied a small number of stage 3 patients, sensitivity of the test was found to be low.

We also studied the efficiency of the clinical diagnostic tests in various combinations. As the number of tests in the combination increased, specificity and positive predictive values increased but sensitivity decreased. Negativity in all seven tests dictated that the diagnosis was not SIS in a high probability.

Efficiency evaluation of the diagnostic tests in each of Zlatkin stages showed that each patient with SIS in Zlatkin stage 3 would react positively to Hawkins test and drop arm test. This dual relation seems to be a pathognomonic sign for Zlatkin stage 3 SIS patients. Especially Neer and horizontal adduction tests had higher efficiency for diagnosis in Zlatkin stage 2 and 3.

1 Meyer SJF, Dalinka MK. Magnetic resonance imaging of the shoulder. Orthop Clin North Am 1990;21:497-513.

2 Wasilevsky SA, Frankl U. Rotator cuff pathology: arthroscopic assessment and treatment. Clin Orthop 1991;267: 65-70.

3 Hawkins RJ, Abrams JS. Impingement syndrome in the absence of rotator cuff tear. Orthop Clin North Am 1987; 18:373-82.

4 Neviaser RJ, Neviaser TJ. Observations on impingement. Clin Orthop 1990;254:60-4.

5 Neer CS. Anterior acromioplasty for chronic impingement syndrome of shoulder. J Bone Joint Surg 1972;54A:41-50. 6 Neer CS. Impingement lesions. Clin Orthop 1983;173: $70-7$

7 Butters KP, Rockwood CA. Office evaluation and management of the shoulder impingement syndrome. Orthop Clin North Am 1988;19:755-65.

8 Neer CS. Cuff tears, biceps lesions and impingement. In: Shoulder reconstruction. Philadelphia: Saunders, 1990:41142 .

9 Magee DJ. Shoulder. In: Orthopedic Physical Assessment. Philadelphia: WB Saunders Company, 1992: 90-142.

10 Warren RF. Shoulder pain. In: Paget S, Pellicci P, Beary JF, eds. Manuel of Rheumatology and outpatient orthopaedic disorders. Boston: Little, Brown, 1993: 99-109.

11 Akgün K. Kronik subakromiyal sikisma sendromunun konservatif tedavisinde ultrasonun etkinligi. [Proficiency Thesis]. Istanbul: University of Istanbul, 1993.

12 Akgün K, Karamehmetoğlu ŞS, Şahin Ü, Tüzün F. Subakromiyal sikisma sendromu klinik tanisinda sikisma (Neer) testinin önemi. Fizik Tedavi ve Rehabilitasyon Dergisi 1997;22:5-7.

13 Hermann B, Rose DW. Stellenwert von Anamnese und klinischer Untersuchung beim degenerativen Impingement Syndrom im Vergleich zu operativen Befunden-eine pyndrom im Vergleich zu operativen Befunde Studie. Z Orthop 1996;134:166-70.

14 Yergason RM. Supination sign. J Bone Joint Surg 1931;131: 60 .

15 Zlatkin MB, Ianotti JP, Roberts MC, Esterhai JL, Dalinka ML, Kressel HY, et al. Rotator cuff tears: diagnostic performance of MRG imaging. Radiology 1989;172: 223-9.

16 Ure BM, Tiling T, Kirchner R, Rixen D. Zuverlassigkeit der klinischen untersuchung der schulter im vergleich zur arthroskopie. Unfallchirurg 1993;96:382-6.

17 Lequesne M, Wilhelm F. Rating indexes: sensitivity, specificity and predictive values or reading the signs: Nostrada-
mus in the twentieth century. In: Lequesne M, Wilhelm F, mus in the twentieth century. In: Lequesne M, Wilhelm F, eds. Methodology for the clinician. Compen

18 Mack LA, Gannon MK, Kilcoyne RF, Matsen SA. Sonographic evaluation of the rotator cuff. Clin Orthop $1988 ; 234: 21-7$

19 Brandt TD, Cardone BW, Grant TH, Post M, Weiss CA. Rotator cuff sonography: a reassessment. Radiology 1989;173:323-7.

20 Farin PV, Jaroma H. Acute traumatic tears of the rotator cuff : the value of sonography. Radiology 1995;197:26973.

21 McCann PD, Bigliani LU. Shoulder pain in tennis players. Sports Med 1994; 17:53-64.

22 Neer CS, Welsh RP. The shoulder in sports. Orthop Clin North Am 1977;8:583-91.

23 Frieman BG, Albert TJ, Fenlin JM. Rotator cuff disease: a review of diagnosis, pathophysiology and current trends in review of diagnosis, pathophysiology and current tre
treatment. Arch Phys Med Rehabil 1994;75:604-9.

24 Pink MM, Jobe FW. Biomechanics of swimming. In: Zachazewski JE, Magee DJ, Quillen WS, eds. Athletic injuries and rehabilitation. Philadelphia: WB Saunders Company, 1996: 317-31.

25 Bak K, Faunl P. Clinical findings in competitive swimmers with shoulder pain. Am J Sports Med 1997;25:254-60. 